\title{
The influence of impregnating chemicals on the carbonization process of viscose fiber cloths Bui Van Tai ${ }^{1}$, Nguyen Hung Phong ${ }^{2}$, Tran Van Chung ${ }^{3}$ \\ Institute of Chemistry and Material, 17 Hoang Sam, Cau Giay, Hanoi
}

\begin{abstract}
The influence of some chemical impregnating such as polyphosphate urea, $\mathrm{ZnCl}_{2}, \mathrm{AlCl}_{3}, \mathrm{FeCl}_{3}, \mathrm{H}_{2} \mathrm{NaPO}_{4}$, $\mathrm{H}_{3} \mathrm{PO}_{4}$ on the carbonization process of viscose fiber cloth at the temperature range from 30 to $700{ }^{\circ} \mathrm{C}$ was studied in detail. $B y$ the thermalgravimetric analysis, the obtained results have showed that the presence of these chemical impreganating agents caused lowering the activation energy and increasing the carbonization viscose mass left at $700^{\circ} \mathrm{C}$. The polyphosphate urea was proven to be a good chemical agent for the carbonization process.
\end{abstract}

Keywords - Viscose fiber, TGA, carbonization process.

\section{INTRODUCTION}

Activated carbon such as powdered or granular forms is well known owing to its widespread application in many fields as a exellent adsorbent for purification, remediation of wastewater and toxic gas generated in industry [1-4]. In the recent years the activated carbon fiber cloths have receive an increasing concern because they exhibit a comparative advantages over the traditional activated carbon, including their application in high technological inovation as use in cell therapy as a support for stem cell growth [5]. Besides, activated carbon fiber cloths belong to the light stable materials with the higher surface area and pore volume that are easily used in different objectives [5]. The activated carbon fiber cloths are resulting from two main processes including physical or thermal and chemical activation [5]. Physical activation involves two stages such as pyrolysis of the fabric used as a precursor, then followe gasifiction with and oxidizing gas like steam or carbon dioxide [6]. On the other hand, the chemical activation process used for preparation of activated carbon cloths consists of (i) impregnation of the precursor with a Lewis acid such as $\mathrm{ZnCl}_{2}, \mathrm{AlCl}_{3}, \mathrm{H}_{3} \mathrm{PO}_{4}$, (ii) pyrolysis of the impregnated precursor, (iii) washing of the obtained product to eliminate the remaining impregnating chemicals before it is allowed to dry. However, in the pyrolysis process there are two steps. The former step is precursor carbon fiber cloth cabonized to remove hydrate and volatile substance, while, the latter is a process of carbonized fiber cloth is activating. The practice has indicated that the role of impregnating agents is essential issues in preparation of carbonization carbon fiber cloths [4]. In this aricle, the influence of impregnating agents such as $\mathrm{FeCl}_{3}, \mathrm{AlCl}_{3}, \mathrm{ZnCl}_{2}, \mathrm{Na}_{2} \mathrm{HPO}_{4}, \mathrm{H}_{3} \mathrm{PO}_{4}$, polyphosphate urea on the chemical the carbonzation process of viscose fiber cloth was studied in detail. It includs their influence on the main factors about kinetics and thermdynamics of carbonization process. The influence of the impregnating agent on carbonizing process was determined based on the kinetics analysis, using thermogravimetric analysis (TGA) and Kissinger equation.

\section{Kinetics backgroud}

Carbonization is a conversion of an organice substance in to carbon or a carbon- containing reidue through pyrolysis [7,8]. The carbonization reaction under thermal decomposition may take play as follows:

$$
\left(\mathrm{C}_{6} \mathrm{H}_{10} \mathrm{O}_{5}\right)_{\mathrm{n}} \text { (solid) } \stackrel{\text { Activatedccomp. }}{\longrightarrow} \longrightarrow \mathrm{C}_{\mathrm{m}} \text { (solid) }+\mathrm{n}_{2} \mathrm{O} \text { (gas) }
$$

According to the thermal decomposition preocess the conversion reaction rate is generally presented as following:

$$
\frac{d \alpha}{d t}=k(T) f(\alpha)
$$

Here $\alpha$ is the extent of conversion at decomposition time $\mathrm{t}$; $\mathrm{k}$ is the reaction rate constant; $\mathrm{f}(\alpha)$ is the reaction mechanism function. The $\frac{d(\alpha)}{d t}$ is the conversion rate at a ceatain temperature, therefore the parameter $\mathrm{k}$ is obtained from the Arrhenius expression as follows:

$$
\mathrm{k}(\mathrm{T})=A e^{-\frac{E a}{R T}}
$$


When the reaction temperature varying with the heating rate of $\beta=\mathrm{dT} / \mathrm{dt}$, the constant $\mathrm{k}(\mathrm{T})$ is given in (3):

$$
\mathrm{k}(\mathrm{T})=\frac{A}{\beta} e^{-\frac{E a}{R T}}
$$

Where $\mathrm{A}$ is the pre-exponenttial factor $\left(\mathrm{mim}^{-1}\right), \mathrm{E}_{\mathrm{a}}$ is the apparent activation energy $\left(\mathrm{kJ}^{\mathrm{mol}} \mathrm{mol}^{-1}\right), \mathrm{R}$ is the gas constant $(8.314$ $\left.\mathrm{kJ} . \mathrm{mol}^{-1} \cdot \mathrm{K}^{-1}\right), \mathrm{T}$ is the absolute temperature (K). Combining exppression (1) and expression (3) resulting in expression (4):

$$
\frac{d(\alpha)}{d t}=\frac{A}{\beta} e \frac{-E_{a}}{R T} f(\alpha)
$$

Denoting:

$$
\frac{d \alpha}{d t}=\frac{d \alpha}{d T} \frac{d T}{d t}
$$

and

$$
\mathrm{g}(\alpha)=\frac{A}{\beta} \int_{0}^{T} e^{-\frac{E a}{R T}} d T
$$

According to Coats-Redferm [9 -11], through intergating the equation (6) we obtained the following expression:

$$
\ln \left[\frac{\mathrm{g}(\alpha)}{\mathrm{T}^{2}}\right]=\ln \left[\frac{\mathrm{d} \alpha}{\mathrm{dt}}\right]=\ln \left[\frac{\mathrm{AR}}{\beta \mathrm{E}}\left(1-\frac{2 \mathrm{RT}}{\mathrm{E}}\right)\right]-\frac{\mathrm{E}}{\mathrm{RT}}
$$

Eq. (2), Eq. (4) and (7) are the fundamental expressions of analytical methods used to calculate kinetic parameters on the basis of TGA data. Here, the activation energy and the pre-exponential factor, reaction constant and entropy would be determined from the slope and the ordinate of theo linear plot of $\ln \left[\frac{d \alpha}{d t}\right]$ versus $1 / \mathrm{TP}$ at a certain rating rate $\beta\left({ }^{0} \mathrm{C} / \mathrm{min}\right)$. Thay are:

$\mathrm{E}_{\mathrm{a}}=-\operatorname{tg} \gamma \times \mathrm{R}$ with $\operatorname{tg} \gamma$ is slope value of the linear plot,

$$
\begin{aligned}
& \mathrm{A}=\frac{e^{b} \times \beta \times E_{a}}{R\left(1-\frac{2 R \bar{T}}{E_{a}}\right)}, \quad b=\ln \left[\frac{A R}{\beta E_{a}}\left(1-\frac{2 R \bar{T}}{E_{a}}\right)\right], \\
& \mathrm{k}=\mathrm{A} e^{-\frac{E a}{R T}}, \quad \mathrm{~A}=\left(\frac{\mathrm{k}_{\mathrm{b}} \mathrm{T}}{\mathrm{h}}\right) \mathrm{e}^{\frac{\Delta \mathrm{S}}{\mathrm{R}}}
\end{aligned}
$$

Here $\mathrm{k}_{\mathrm{b}}$ is Boltzmann constant, and $\mathrm{h}$ is Plank constant. From here other parameters would be calculated by this way:

$$
\begin{gathered}
\Delta \mathrm{H}=\mathrm{E}+(\Delta \mathrm{n}-1) \mathrm{RT}, \text { with } \Delta \mathrm{n}=-2, \\
\Delta \mathrm{H}=\mathrm{E}-3 \mathrm{RT}, \quad \Delta \mathrm{G}=\Delta \mathrm{H}-\mathrm{T} . \Delta \mathrm{S}
\end{gathered}
$$

\section{EXPERIMENTAL PROCEDURE}

\subsection{Chemicals:}

- Viscose fiber cloth made in Japan.

- $\quad \mathrm{H}_{3} \mathrm{PO}_{4}$ (Analytical purity ) from China.

- $\mathrm{NaH}_{2} \mathrm{PO}_{4}$ (Analytical purity) from China. 
- Urea (Analytical purity) from China.

- $\mathrm{AlCl}_{3}$ (Analytical purity) from China.

- $\mathrm{FeCl}_{3}$ (Analytical purity) from China.

- $\mathrm{ZnCl}_{2}$ (Analytical purity) from China.

\subsection{Apparatus}

TA Instruments TGA 2950 Thermogravimetric Analyzer, USA and 409 PC NETSZCH, GERMANY

\subsection{Experimental procedure}

\subsubsection{Cloth samples}

The cleaned viscose fiber cloth samples were cut off in small speces in size of $20 \times 30 \mathrm{~cm}$. The solutions suitable for impregnation of precursor (cleaned viscose fiber cloth) were prepared by the dissolution of these reagents in distilled water. The viscose fibers were impregnated in each impregnating chemical solution with the certain time, then after dried at ambient temperature to remove water, was taken to analyze by thermogravimetric analysis (TGA).

\section{RESULTS AND DISCUSSION}

\subsection{Thermogravimetric analysis (TGA)}

\subsubsection{The thermogravimetric analysis (TGA) of precusor material (viscose fiber cloth)}

The TGA precursor denoted $\mathrm{M}(0)$ was carried out under nitrogen atmosphere and in the temperature range from 30 to $700^{\circ} \mathrm{C}$ with the hating rate $5^{0} \mathrm{C} / \mathrm{min}$. The TGA of viscose fiber cloth is present in Figure 1.

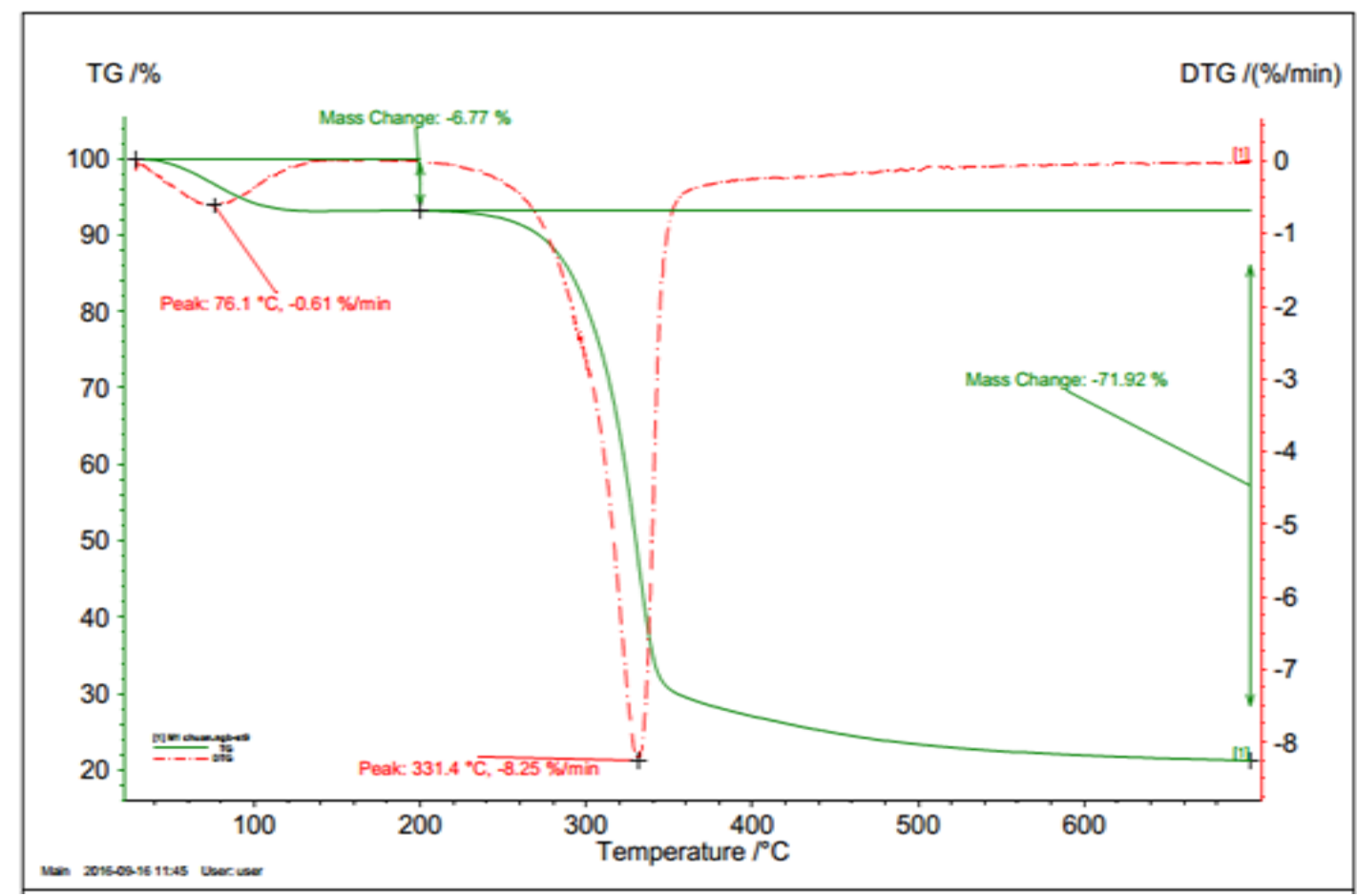

FIGURE 1. TGA CURVE OF THE EXPERIMENT A VISCOSE FIBER CLOTH

The figure 1. shows TGA of viscurse untreated with impregating chemical that when at the temperature $<135^{\circ} \mathrm{C}$ there was a weight loss of $6.77 \%$ due to removing water from fiber surface, from 135 to $300{ }^{\circ} \mathrm{C}$, the weight loss is due to the removing water within fiber, at $300^{\circ} \mathrm{C}$ the weight loss reach to $20 \%$. The carbonization of fiber was carried out in the temparature range from 300 to $360^{\circ} \mathrm{C}$ with the weight loss of about $50 \%$. The carbonization continued to $700^{\circ} \mathrm{C}$ with the fiber mass remaining in $20 \%$. According to [8] during carbonization process, thermal decomposition of raw materials eliminates non-carbon elements such as oxygen, hydrogen and nitrogen lead to a carbon skeleton (char) with a rudimentary pore structure. 
3.1.2 The thermogravimetric analysiz (TGA) of viscose fiber cloth impregnated by polyphosphate urea solution of $5 \%(w t / v), M(1)$

The before carbonization, the viscose fiber cloth was impregnated in 5\% (wt/v) -polyphosphate urea for the certain time at room temperature. The influence of the polyphoshate urea as impregnating chemical on the carbonization process of this sample was determined by TGA curve (figure 2). Process of this carbonization was carried out under the condition with the temperature range from 30 to $700^{\circ} \mathrm{C}$ and the hating rate of $5^{\circ} \mathrm{C} / \mathrm{min}$, atmosphere of nitrogen.

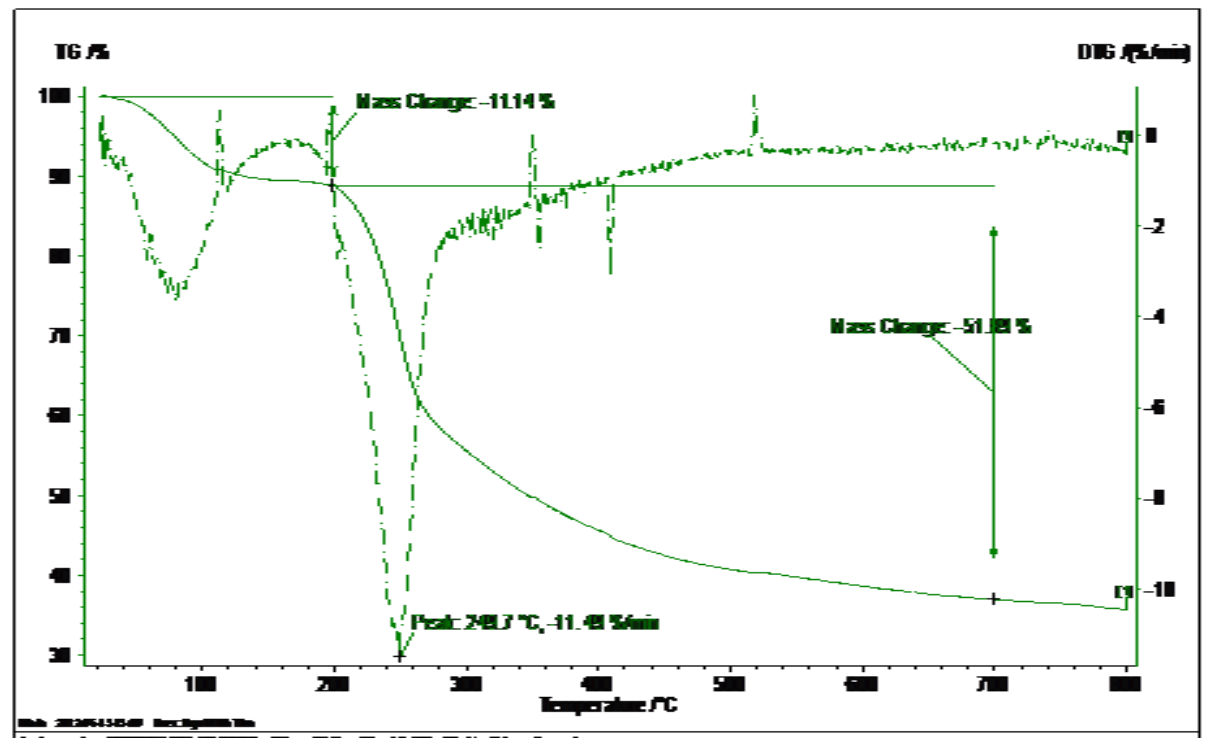

\section{FIGURE 2. TGA CURVE OF THE EXPERIMENTAL VISCOSE FIBER CLOTH CLOTH IMPREGNATED IN $5 \%$} SOLUTION POLYPHOSPHATE UREA

The figure 2. shows TGA of viscurse with impregating chemical (polyphosphate urea $5 \% \mathrm{wt} / \mathrm{v}$ ) that when at the temperature $<110^{\circ} \mathrm{C}$ there was a weight loss of $11.14 \%$ due to removing water from fiber surface, from 110 to $200{ }^{\circ} \mathrm{C}$, the weight loss is due to the removing water within fiber. At the temperature range from 200 to $700^{\circ} \mathrm{C}$ the weight remaining in $39 \%$. This value of the pregnating viscose fiber cloth is higher than of those precursor (20\%).

An experiment of carbonization of viscose fiber cloth impregnated in $5 \% \mathrm{ZnCl}_{2}, \mathrm{M}(2)$ solution, its TGA was present in figure 3.

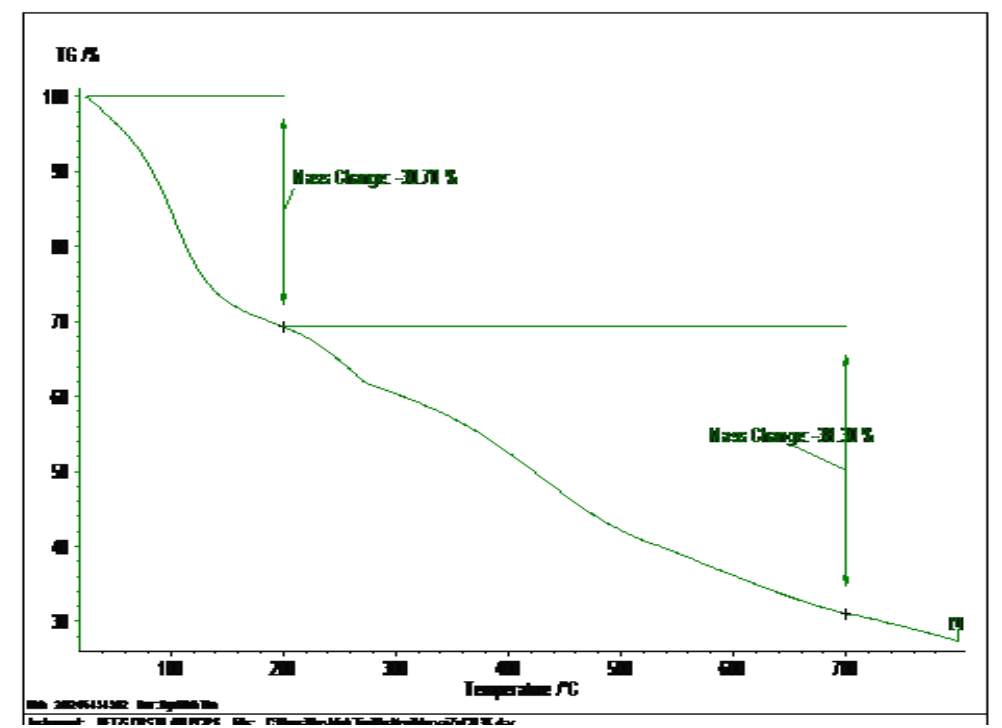

\section{FIGURE 3. TGA CURVE OF THE EXPERIMENTAL VISCOSE FIBER CLOTH IMPREGNATED IN 5\% SOLUTION $\mathrm{ZNCL}_{2}$}

Here, the weight loss of about $20 \%$ at the temperature $<180^{\circ} \mathrm{C}$ and the viscose fiber cloth left of about $30 \%$ at $700^{\circ} \mathrm{C}$ were 
observed.

Other experimants of the viscose fiber cloth were impregnated in the different pregnating solutions such as $5 \% \mathrm{FeCl}_{3} \mathrm{M}(3)$; $5 \% \mathrm{Al} \mathrm{Cl}_{3}, \mathrm{M}(4), 5 \% \mathrm{Na}_{2} \mathrm{HPO}_{4} \mathrm{M}(5) ; 5 \%$ axit $\mathrm{H}_{3} \mathrm{PO}_{4} \mathrm{M}(6)$ to continue investigating the influence on the carbonization. The TGA curves of these samples were present in figure 4 .

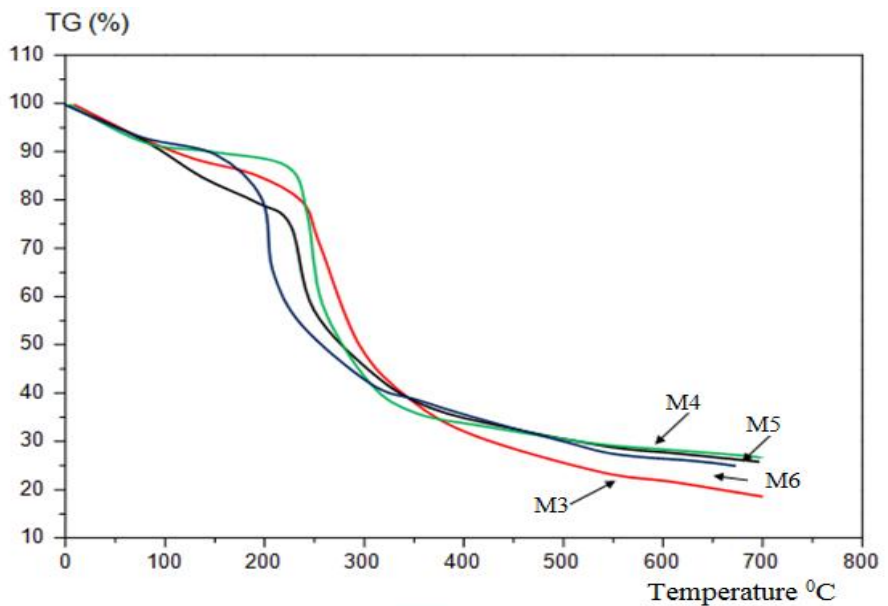

\section{FIGURE 4. TGA CURVES OF THE EXPERIMENTAL VISCOSE FIBER CLOTH IMPREGNATED IN $5 \%$ SOLUTIONS OF FECL $L_{3}, \mathrm{M}(3) ; \mathrm{ALCL}_{3}, \mathrm{M}(4) ; \mathrm{NA}_{2} \mathrm{HPO}_{4}, \mathrm{M}(5) ; \mathrm{H}_{3} \mathrm{PO}_{4} \mathrm{M}(6)$.}

Here, analogy with the $\mathrm{M}(2)$ the their weight loss of about $30 \%$ at the temperature $<180^{\circ} \mathrm{C}$ and their viscose fiber cloth mass left of about from 25 to $28 \%$ at $700^{\circ} \mathrm{C}$ were observed. Studing the imfluence of the impregnating chemcals on the carbonization process of the viscose fiber cloth as suggested above, the carbonizating temrperature of these samples was slower than of the precursor. Besides, the weight mass left at $700^{\circ} \mathrm{C}$ was higher than of precursor, in which for the polyphosphate urea impregnated sample, the weight mass left was 39\%, the highest value comparing with other impregnating agents. The highest weight mass left of viscose fiber cloth at $700^{\circ} \mathrm{C}$ relating with polyphosphate urea can be illustrated in [9]. According to this author the two negatively charged oxygen atoms in phosphate ion can align themselves adjacent to similar atoms accociated with the cellulose molecule. This occurs most readily with the $\mathrm{HPO}_{4}{ }^{2-}$ ion, explaining why it is so effective as a retardant in this system. A part from that, the attachment of two adjaent $\mathrm{HPO}_{4}{ }^{2-}$ ion on a cellulose molecule enables water to be eliminated between them on thermal treatment, thus providing a protective skin for various part of the internal structure.

\subsection{Influence of chemical impregnating agents on carbonization of viscose fiber cloth}

\subsubsection{The influence of chemical impregnating agents on carbonization temperature}

The influence of chemicalc agents on carbonization process of viscose fiber cloth was determined through carbonization temperature: initial $\mathrm{T}(\mathrm{i})$ and final $\mathrm{T}(\mathrm{f})$, the temperature range $\mathrm{T}(\mathrm{f})-\mathrm{T}(\mathrm{i})$, the fiber cloth weight $\mathrm{m}$ (i) at begining $\mathrm{T}(\mathrm{i})$ and $\mathrm{m}(\mathrm{f})$ at ending $\mathrm{T}(\mathrm{f})$ and $\mathrm{T}_{1 / 2}$ the temperature corresponding the fiber cloth weight left in $50 \%$ in carbonizing process. From the obtained TGA curves the influence of chemical agents on carbonizing process of viscose fiber cloth were present in table 1 .

TABLE 1

INFLUENCE OF CHEMICAL AGENTS ON CARBONIZATION

\begin{tabular}{|c|c|c|c|c|c|}
\hline Samples & $\mathbf{T}_{(\mathrm{i})}\left({ }^{\circ} \mathbf{C}\right)$ & $\mathbf{m}_{(\mathrm{i})}(\%)$ & $\mathbf{T}_{(\mathrm{f})}\left({ }^{\circ} \mathrm{C}\right)$ & $\mathbf{m}(\mathrm{f})(\%)$ & $\mathbf{T}^{1 / 2}\left({ }^{0} \mathbf{C}\right)$ \\
\hline M0 (unimpregnated) & 300 & 86 & 360 & 20 & 340 \\
\hline M1(with 5\% Polyphosphate urea ) & 220 & 89 & 700 & 39 & 270 \\
\hline M2 (with $5 \% \mathrm{ZnCl}_{2}$ ) & 200 & 74 & 700 & 25 & 270 \\
\hline $\mathrm{M} 3\left(\right.$ with $5 \% \mathrm{FeCl}_{3}$ ) & 250 & 86 & 650 & 25 & 350 \\
\hline M4 (with $5 \% \mathrm{AlCl}_{3}$ ) & 240 & 85 & 700 & 28 & 280 \\
\hline M5 (with 5\% $\mathrm{Na}_{2} \mathrm{HPO}_{4}$ ) & 230 & 88 & 700 & 26 & 350 \\
\hline M6 (with $5 \% \mathrm{H}_{3} \mathrm{PO}_{4}$ ) & 210 & 89 & 700 & 25 & 300 \\
\hline
\end{tabular}


The obtained data from the table 1. indicate that the presence of chemical impregnating agents cause lowering the carbonization beginning temperture (T(i) and elevating the carbonation final temperature comparing with the precursorunimpregnated viscose fiber cloth. This was explained the interaction betweent chemical agents with cellulose mollecules on their surface.

\subsubsection{The influence of chemical impregnating agents on kinetics}

Basing on the TGA curves of the viscose fiber cloth unpregated pregnated by chemical agents, the plots of $\ln \frac{d \alpha}{d t}$ vs. $\frac{1}{T}$ were determined present in figure 5 .

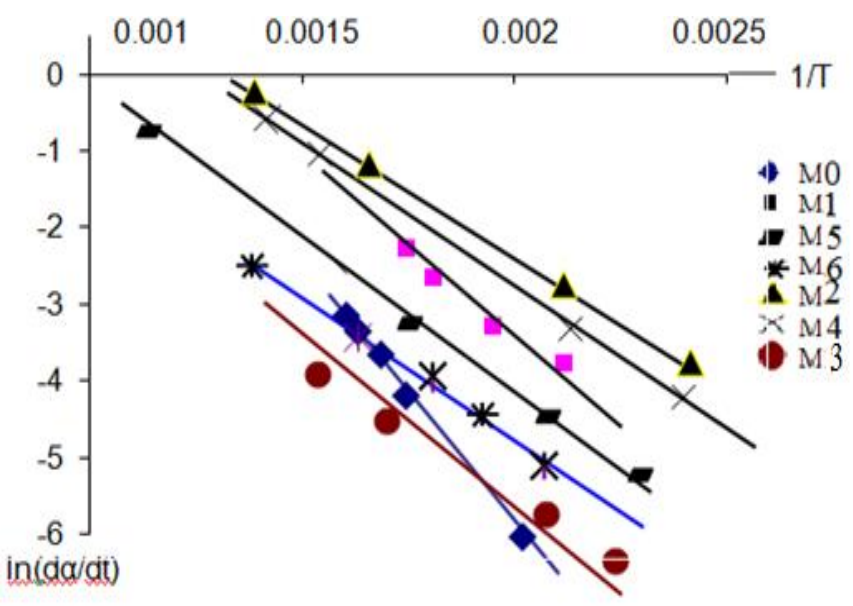

Figure 5. THE PLOTS OF $\ln \frac{d \alpha}{d t}$ vS. $\frac{1}{T}$

From the plots of $\ln \frac{d \alpha}{d t}$ vs. $\frac{1}{T}$ the kinetic parameters of the linear equation (7) such as activation energy, pre-exponential factor and rate constant, were determined present in table 2.

TABLE 2

THE KINETIC PARAMETERS OF CARBONIZATION PROCESS

\begin{tabular}{|c|c|c|c|}
\hline Samples & $\begin{array}{c}\mathbf{E}_{\mathbf{a}} \\
(\mathrm{kJ} / \mathrm{mol})\end{array}$ & pre-exponential factor $\mathbf{A}\left(\mathbf{s}^{-1}\right)$ & Rate constant \\
\hline M0 & 63.8 & $1.65 \times 10^{11}$ & $k=1.65 \times 10^{11} \cdot e^{\frac{-63,81}{R T}}$ \\
\hline M1 & 28.4 & $2.38 \times 10^{8}$ & $k \cdot 38 x 10^{8} \cdot e^{\frac{-28,4}{R T}}$ \\
\hline M2 & 20.7 & $5.51 \times 10^{7}$ & $k \cdot 51 \times 10^{7} \cdot e^{\frac{-20,7}{R T}}$ \\
\hline M3 & 22.7 & $3.28 \times 10^{8}$ & $k 1.28 x 10^{8} \cdot e^{\frac{-22,5}{R T}}$ \\
\hline M4 & 17.3 & $1.57 \times 10^{8}$ & $k \cdot 57 x 10^{8} \cdot e^{\frac{-17,3}{R T}}$ \\
\hline M5 & 25.3 & $2.87 \cdot 10^{8}$ & $k=2.87 x 10^{8} \cdot e^{\frac{-24,73}{R T}}$ \\
\hline
\end{tabular}

The obtained data showed that the presence of chemical impregnating agents cause lowering the activation energy of carbonization process. These results were fitted the work $[\mathrm{x}]$ 


\subsubsection{Effect of heating rate on the carbonization process of polyphosphate urea impregnated viscose fiber cloth}

The experimental data have indicated the advantages of the polyphosphate urea impregnating on viscose fiber cloth, therefore a study of Influence of heating rate on the carbonization process of polyphosphate urea impregnated viscose fiber cloth was carried out. This effect was present in the figure 6.

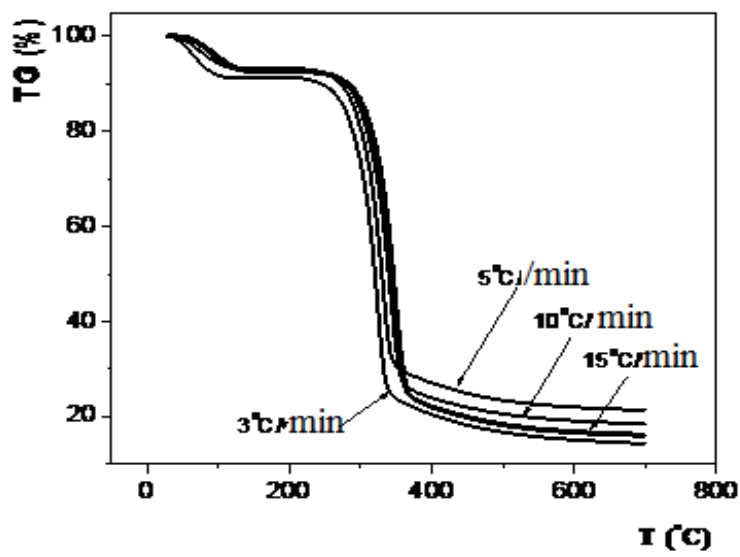

FIGURE 6. THE EFFECT OF HEATING RATE ON CARBONIZATION PROCESS

Basing on the obtained TGA curves, the influence of heating rate on kinetic parmeters of carbonization prcess of polyphosphate urea impregnated viscose fiber cloth were present in table 3 .

TABLE 3

INFLUENCE OF THE HEATING RATE ON CARBONIZATION PROCESS

\begin{tabular}{|c|c|c|c|}
\hline $\begin{array}{c}\text { Heating rate } \\
\boldsymbol{\beta}^{0} \mathrm{C} / \mathbf{m i n}\end{array}$ & $\begin{array}{c}\text { pre-exponential factor } \mathbf{A}\left(\mathbf{s}^{-}\right. \\
\mathbf{1})\end{array}$ & $\begin{array}{c}\mathbf{E}_{\mathbf{a}} \\
(\mathbf{k J} / \mathbf{m o l})\end{array}$ & Rate constant \\
\hline 3 & $2.6 .10^{7}$ & 28.91 & $k=2.6 \times 10^{7} \cdot e^{\frac{-28,91}{R T}}$ \\
\hline 5 & $4.5 \times 10^{7}$ & 28.87 & $k=4.5 \times 10^{7} \cdot e^{\frac{-28,87}{R T}}$ \\
\hline 10 & $9.1 \times 10^{7}$ & 28.78 & $k=9.1 \times 10^{7} \cdot e^{\frac{-28,78}{R T}}$ \\
\hline 15 & $1.2 \times 10^{8}$ & 28.69 & $k=1.2 \times 10^{8} \cdot e^{\frac{-28,69}{R T}}$ \\
\hline
\end{tabular}

The obtained results showed that the heating rates increasing cause the pre-exponent coeffients increasing and activation energy decreasing lightly. The pronounced increase of pre - exponential factor can promote the reaction rate increasing like suggested by [4].

\subsubsection{The influence of chemical impregnating agents on thermodynamics}

Basing on the equation (7) combining with the experimental data, the change in entropy, enthalpy and Gibbs free energy corresponding to the carbonization process were calculated present in table 4 .

TABLE 4

THE INFLUENCE OF CHEMICAL IMPREGNATING AGENTS ON THERMODYNAMICS

\begin{tabular}{|c|c|c|c|}
\hline Samples & $\begin{array}{c}\Delta \mathbf{S} \\
(\mathbf{k J} / \mathbf{m o l} . \mathbf{K})\end{array}$ & $\begin{array}{c}\Delta \mathbf{H} \\
(\mathbf{k J} / \mathbf{m o l})\end{array}$ & $\begin{array}{c}\Delta \mathbf{G} \\
(\mathbf{k J} / \mathbf{m o l})\end{array}$ \\
\hline M0 & 0.186 & 58.60 & -58.62 \\
\hline M1 & 0.132 & 24.20 & -45.60 \\
\hline M2 & 0.122 & 15.44 & $-54,60$ \\
\hline M3 & 0.163 & 17.15 & -84.42 \\
\hline M4 & 0.147 & 20.21 & -72.60 \\
\hline M5 & 0.109 & 12.49 & -50.23 \\
\hline M6 & 0.120 & 16.39 & -51.25 \\
\hline
\end{tabular}


The obtained experimental data the carbonization process proceed spontaneously corresponding to $\Delta \mathrm{S}>0, \Delta \mathrm{G}<0$. In this case of $\Delta \mathrm{S}>0$ indicating a thermal decomposition reaction of viscose fiber might occur with non structured activated complex comparing with the initial reactants. This can be suggested that the carbonization reaction is classified as fast [8]. The obtained experimental data from table 4 show that the presence of chemical agents such as polyphosphate urea, $\mathrm{ZnCl}_{2}, \mathrm{FeCl}_{3}$, $\mathrm{AlCl}_{3}, \mathrm{Na}_{2} \mathrm{HPO}_{4}$ and $\mathrm{H}_{3} \mathrm{PO}_{4}$ cause a change in $\Delta \mathrm{S}, \Delta \mathrm{H}$ and $\Delta \mathrm{G}$, however, all thermodynamic parameters indicating the carbonization process is endothermic reaction occurring spontaneously.

\section{CONCLUSION}

The study of the influence of chemical impregnating on viscose fiber cloth was carried out in detail. The chemical impregnating agents such as polyphosphate urea, $\mathrm{ZnCl}_{2}, \mathrm{FeCl}_{3}, \mathrm{AlCl}_{3}, \mathrm{Na}_{2} \mathrm{HPO}_{4}$ and $\mathrm{H}_{3} \mathrm{PO}_{4}$ have been used as chemical agents for carbonization process of viscose fiber cloth. The presence of these agents might cause the change in the mass of viscose fiber remaining after carbonization at temperature from 30 to $700^{\circ} \mathrm{C}$. The carbonization process of viscose fiber occurred spontaneously and along endothermic reaction. The main effect of chemical agents is to lowering the carbonization temperature of impregnated viscose fiber comparing with precursor. The chemical agent as polyphosphate urea was proven with the most effective advantage in carbonization of viscose fiber with the highest mass left reached to $39 \%$.

\section{REFERENCES}

[1] T. J. Bandosz, Activated Carbon Surfaces in Environmental Remediation, Academic Press, 2006.

[2] G.Mezohegyi, et. al Fabregat, "Towards advanced aqueous dye removal processes: a short review on the versatile role of activated carbon, ”Journal of Environmental Management, vol.102, pp.148-164, 2012.

[3] J. Rivera-Utrilla et. al "Activated carbon modifications to enhance its water treatment applications. An overview", Journal of Hazardous aterials, vol.187, pp.1-23, 2011.

[4] Ana Lea Cukierman, Development and Environmental Applications of Activated Carbon Cloths. Chemical Engineering Volume 2013, Article ID 261523,31pages

[5] A. Linares-Solano and D. Cazorla-Amor' os, "Adsorption on activated carbon fibers," in Adsorption By Carbons, E.J. Bottani and J.M.D.Tasc' on, Eds., Chapter 17, pp.431-449, Elsevier, Oxford, UK, 2008.

[6] F. Rodr'1guez-Reinoso, "Production and applications of activated carbons," in Handbook of Porous Solids, F.Sch" uth, K. S. W.Sing, and J. Weitkamp, Eds., Chapter 4,8,1, pp.1766-1827, Wiley-VCH, Weinheim, Germany, 2002.

[7] Tao Wang, et al. Kinetics of Thermal Degradation of Viscose Fiber and Fire Retardant Viscose Fiber, Journal of Engineered Fibers and Fabrics Volume 9, Issue 2 - 2014.

[8] Sevdalina Turmanova, Kinetics of Nonisothermal Degradation of Some Polymer Composites: Change of Entropy at the Formation of the Activated Complex from the Reagents, Journal of Thermodynamics Volume 2011, Article ID 605712, 10 pages.

[9] P. Budrugeac and E. Segal, "Some methodological problems concerning nonisothermal kinetic analysis of heterogeneous solid-gas reactions," International Journal of Chemical Kinetics, vol. 33, no. 10, pp. 564-573, 2001.

[10] A. Ruvolo-Filho and P. Curti, "Chemical kinetic model and thermodynamic compensation effect of alkaline hydrolysis in waste poly(ethylene terephtalate) in non-aqueous ethylene glycol solution," Industrial and Engineering Chemistry Research, vol. 45, no. 24, pp. 7985-7996, 2006.

[11] D.S.Dias, et al Non-isothermal decomposition kinetics of the interaction of poly(ethylene terephthalate) with alkyd varnish,” Journal of Thermal Analysis and Calorimetry, vol. 94, no. 2, pp. 539-543, 2008. 